\title{
Sedation Practices for Gastrointestinal Endoscopy in Europe, North America, Asia, Africa and Australia
}

\author{
Spiros D. Ladas ${ }^{a}$ Yoshiharu Satake $^{b} \quad$ Ibrahim Mostafac John Morse ${ }^{d}$ \\ ${ }^{a}$ Hepatogastroenterology Division, 1st Department of Internal Medicine - Propaedeutic, Laiko General Hospital of \\ Athens, Medical School, Athens University, Athens, Greece; ${ }^{b}$ Division of Gastroenterology, Department of Internal

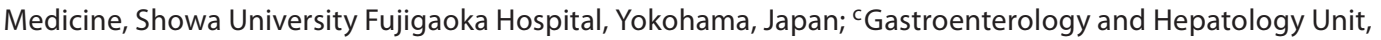 \\ Theodor Bilharz Research Institute, Cairo, Egypt; ${ }^{\mathrm{d} C}$ Cowichan District Hospital, Duncan, B.C., Canada
}

\section{Key Words}

Sedation · Gastroscopy · Colonoscopy

\begin{abstract}
Gastroscopy and colonoscopy are standard practice for diagnosing upper gastrointestinal and colonic diseases. Sedation improves tolerance of the endoscopic procedures, but may be responsible for about $50 \%$ of the complication rate of the examination. Data from countries of the five continents regarding the rate of using sedation for gastrointestinal endoscopy are rare. We performed a literature search (PubMed) to identify published national or international studies and summarize data on the rate of using sedation for diagnostic gastrointestinal endoscopic procedures in countries of Europe, North America, Asia, Africa and Australia. In continents where data were not available, we used mailed questionnaires to endoscopy centers in countries of these continents. Our data indicate that the use of sedation for diagnostic gastrointestinal endoscopy is high in North America and Australia, but varies considerably among countries in Europe, Asia and Africa.

Copyright $\odot 2010$ S. Karger AG, Basel
\end{abstract}

\section{Introduction}

Routine diagnostic gastrointestinal (GI) endoscopy is the standard practice for diagnosing esophageal, gastric, duodenal and colonic diseases. It has very low complication and mortality rates [1] and may be done without or with a variety degree of conscious sedation, using a wide range of intravenous sedatives. The use of sedation improves the tolerance and acceptance of the examination [2], but increases the cost of the procedure and is responsible for about $50 \%$ of the GI endoscopy complication rates [3]. The decision to use premedication may be influenced by national and cultural differences among countries, as well as patient wishes and endoscopist's attitude to the examination.

The aim of this study was to summarize and present data from countries of the five continents on the rate of sedating patients for diagnostic gastroscopy and colonoscopy. For this purpose we searched PubMed to identify relevant English language publications, using proper key words. We identified a few national or international studies from Europe and North America investigating the rate of using conscious sedation for diagnostic GI endoscopy, but there were no data available from Australia, Asia or Africa. Therefore, for the purpose of this investigation, two of the authors conducted a mail questionnaire survey in these three continents.

Prof. Spiros D. Ladas, MD, $\mathrm{PhD}$

1st Department of Internal Medicine - Propaedeutic

Laiko General Hospital of Athens

Ag. Thoma 17, GR-11527 Athens (Greece)

Tel. +30 210745 6261, Fax +30 210779 1839, E-Mail sdladas@otenet.gr 


\section{Upper GI Endoscopy}

Published national surveys have documented major differences among countries in the rate of using sedation for routine diagnostic gastroscopy in Europe. In Finland, only $1.5 \%$ of the endoscopists use sedation in about $25 \%$ of their patients [4]. In Spain, sedation is used in 17\% of gastroscopies [5], and in Germany, most endoscopists use sedation in $10-50 \%$ of their patients [6]. In the UK, the sedation rate decreased by $54 \%$, from $70 \%$ in 1990 to $32 \%$ in 1998 [7], while in Switzerland it increased, with 77\% of the endoscopists sedating their patients in 2003 [8]. The results of a recent European survey (29 countries) showed that in about $50 \%$ of the countries, less than $25 \%$ of the patients undergo routine diagnostic upper GI endoscopy with sedation [9] (fig. 1). However, a wide variation of the rate of sedated gastroscopy was confirmed, as in $7 \%$ of the countries the sedation rate was higher than $75 \%$.

A variety of sedatives were in use in these 29 countries. These included diazepam, midazolam, meperidine, fentanyl and propofol, with the most popular being midazolam and propofol [9]. It is important to note that in 8 of 12 countries where an anesthesiologist sedated the patients and propofol was included in the list of the preferred sedatives, the sedation rate was less than 25\% [9].

Since most gastroscopy complications are cardiopulmonary, especially in sedated patients, monitoring is important to diagnose and prevent them [2,3]. With the increasing rate of using propofol, the rate of respiratory depression could increase and therefore monitoring these patients is mandatory. According to a European survey [9], monitoring equipment was available in $91 \%$ of the responders' endoscopy units. However, in as much as $46 \%$ of the countries, monitoring was not available in the majority of endoscopy units. The lack of monitoring could also be a factor influencing the low sedation rate reported for these countries.

Data from the USA show that the vast majority (>98\%) of upper GI endoscopies are performed with sedation. Sedatives mainly used are benzodiazepines (74\%) and propofol (26\%). Endoscopists monitor their patients with (at least) pulse oximetry (99\%) [10].

Y. Satake received replies to his questionnaire from 45 centers in 7 countries in Asia and Australia. All upper GI endoscopies seem to be performed under sedation in Australia ( 2 centers). However, there is a large variation in the rate of using sedation among Asian countries, varying from $50-100 \%$ (fig. 2). In many Asian countries, not a few upper GI endoscopies are performed without sedation. Among sedatives, midazolam is used in all of

Sedation Practices for Gastrointestinal Endoscopy

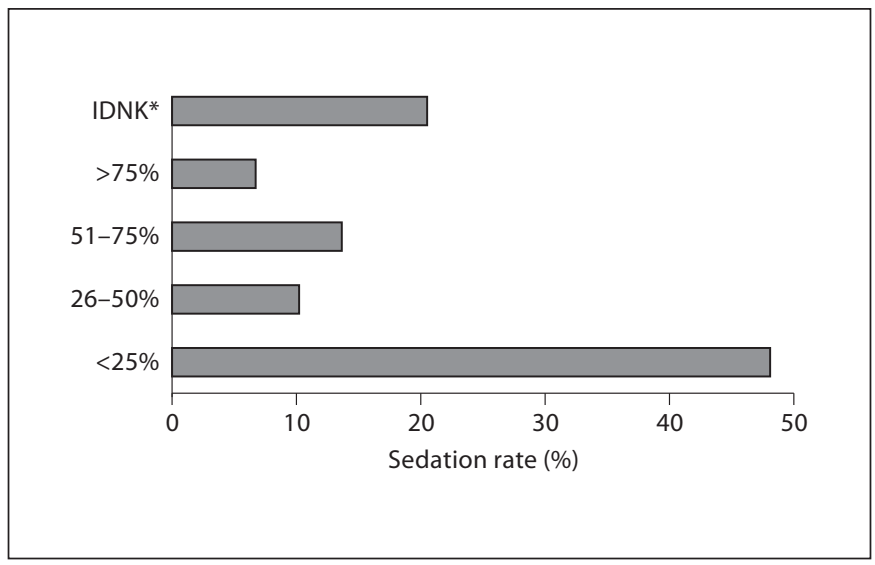

Fig. 1. Reported (questionnaire) sedation rates for diagnostic gastroscopy in 29 European countries in which endoscopy societies are members of ESGE. * IDNK: Data not available.

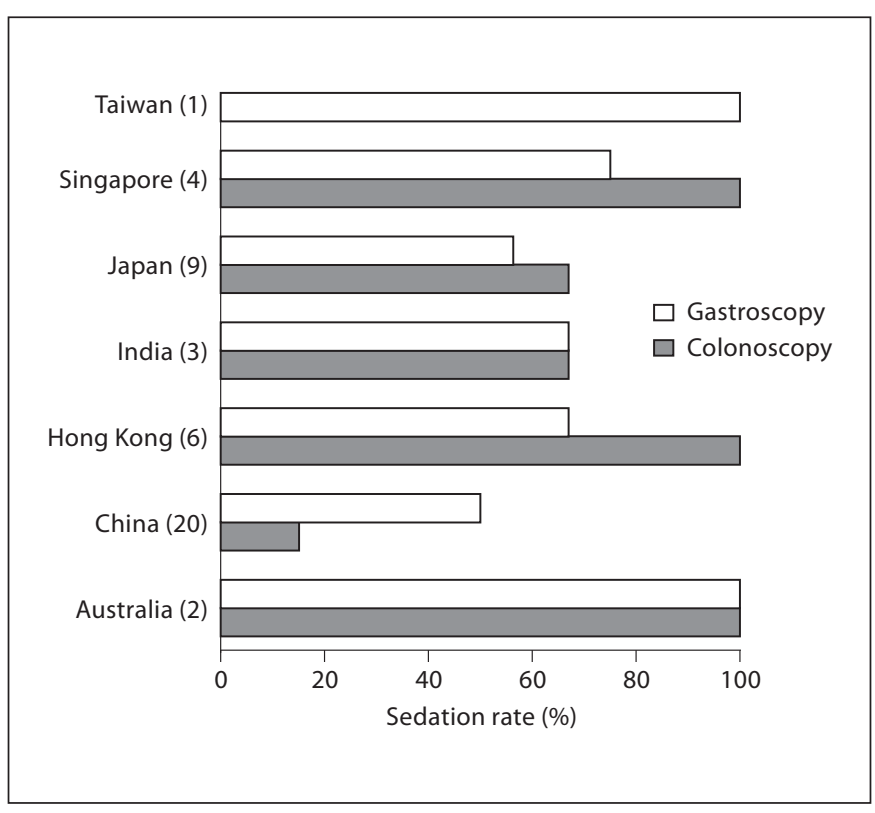

Fig. 2. Reported (questionnaire) sedation rates for diagnostic gastroscopy and colonoscopy in Asian countries and Australia. The numbers in parentheses represent the number of endoscopy centers which replied to the questionnaire.

countries and use of propofol has been experienced in every country which replied to the questionnaire. In most of the facilities, except of one in Australia, propofol is used in the presence of anaesthesiologist.

Data from Africa are only available from the ESGE mailed questionnaire study [9] where Morocco, Tunisia 
and Egypt participated as ESGE members. The sedation rates for upper GI endoscopy reported from these countries ranged between 25 and $50 \%$.

\section{Colonoscopy}

Like gastroscopy, in the past 5 years published studies from Europe show major differences among countries, as well as within the same country, of the rate of using sedation for colonoscopy. In a study of 14 Norwegian centers, the mean sedation rate was $37 \%$ (range 6-97\%) [11]. Another study from 33 district hospitals in Portugal showed that sedation was used in $24.5 \%$ of the procedures [12], which is lower than the rate of $45.5 \%$ reported from 34 endoscopy centers from Romania [13]. A study from 278 centers, including 12,835 consecutive colonoscopies, in Italy showed that sedation and/or analgesia was used in about $50 \%$ of the patients [14]. In contrast, a study on colonoscopy practice in the UK, including 68 endoscopy units and 9,223 colonoscopies, showed a sedation rate of $94.6 \%$ [15]. A recently published study, including 21 centers from 11 European countries, confirmed the above data, reporting most patients $(>85 \%)$ received conscious sedation in 9 centers, deep sedation in 5 centers and no sedation for most patients in 2 centers [16].
Midazolam (47\%) for sedation and opioids (33\%) for analgesia was the current sedation practice in 21 centers in 11 European countries [16]. Like upper GI endoscopy, pulse oximetry was used in $77 \%$ of the colonoscopies [17]. Lower figures have been reported in a multicenter study of colonoscopy practices in Italy [18]. In the USA and Canada, sedation and analgesia are used in almost all colonoscopies [10]. The mailed questionnaire survey by Y. Satake showed similar data to those of his gastroscopy survey. All colonoscopies seem to be performed under sedation in Australia, but there is a large variation in the rate of using sedation (50-100\%) among Asian countries (fig. 2). In several Asian countries, many colonoscopies are performed without sedation. Among sedatives, midazolam is used in all countries and the use of propofol has been experienced in every country which replied to the questionnaires.

\section{Conclusions}

The above data indicate that in North America and Australia, almost all routine diagnostic endoscopic procedures are performed with conscious sedation. However, in Europe, Asia and Africa, the sedation rate varies among countries and even among centers of the same country.

\section{References}

1 American Society for Gastrointestinal Endoscopy: Complication of upper GI endoscopy. Gastrointest Endosc 2002;55:748-793.

$\checkmark 2$ Bell GD: Preparation, premedication, and surveillance. Endoscopy 2004;36:23-31.

3 Lazzaroni M, Bianchi Porro G: Preparation, premedication, and surveillance. Endoscopy 2005;37:101-109.

4 Ristikankare MK, Julkunen RJ: Premedication for gastrointestinal endoscopy is a rare practice in Finland: a nationwide survey. Gastrointest Endosc 1998;47:204-207.

5 Campo R, Brullet E, Junquera F, Puig-Divi V, Vergara M, Calvet X, Marco J, Chuecos M, Sanchez A, Alcazar A, Ruiz M, Puig M, Real J: Sedation in digestive endoscopy. Results of a hospital survey in Catalonia (Spain). Gastroenterol Hepatol 2004;27:503-507.

-6 Sieg A, Hachmoeller-Eisenbach U, Heisenbach T: How safe is premedication in ambulatory endoscopy in Germany? A prospective study in gastroenterology specialty practices (in German). Dtsch Med Wochenschr 2000; 125:1288-1293.

7 Mulcahy HE, Hennessy E, Connor P, Rhodes B, Patchett SE, Farthing MJ, Fairclough PD: Changing patterns of sedation use for rou- tine out-patient diagnostic gastroscopy between 1989 and 1998. Aliment Pharmacol Ther 2001;15:217-220.

8 Heuss LT, Froehlich F, Beglinger C: Changing patterns of sedation and monitoring practice during endoscopy: results of a nationwide survey in Switzerland. Endoscopy 2005;37:161-166.

9 Ladas SD, Aabakken L, Rey JF, et al: Use of sedation for routine diagnostic upper gastrointestinal endoscopy: a European Society of Gastrointestinal Endoscopy Survey of National Endoscopy Society Members. Digestion 2006;74:69-77.

10 Cohen LB, Wecsler JS, Gaetano JN, et al: Endoscopic sedation in the United States: results from a nationwide survey. Am J Gastroenterol 2006;101:967-974.

11 Hoff G, Bretthauer M, Huppertz-Hauss G, et al: The Norwegian Gastronet project: Continuous quality improvement of colonoscopy in 14 Norwegian centres. Scand J Gastroenterol 2006;41:481-487.

12 Cremers MI, Marques-Vidal P; NGHD: Colonoscopies in Portuguese district hospitals: a multicentric transverse study. Dig Liver Dis 2006;38:912-917.
13 Sporea I, Popescu A, Sandesc D, et al: Sedation during colonoscopy. Rom J Gastroenterol 2005;14:195-198.

14 Radaelli F, Meucci G, Minoli G, Italian Association of Hospital Gastroenterologists (AIGO): Colonoscopy practice in Italy: a prospective survey on behalf of the Italian Association of Hospital Gastroenterologists. Dig Liver Dis 2008;40:897-904.

15 Bowles CJ, Leicester R, Romaya C, et al: Prospective study of colonoscopy practice in the UK today: are we adequately prepared for national colorectal cancer screening tomorrow? Gut 2004;53:277-283.

16 Harris JK, Vader JP, Wietlisbach V, et al: Variations in colonoscopy practice in Europe: a multicentre descriptive study (EPAGE). Scand J Gastroenterol 2007;42:126-134.

17 Froehlich F, Harris JK, Wietlisbach V, et al: Current sedation and monitoring practice for colonoscopy: an International Observational Study (EPAGE). Endoscopy 2006;38: 461-469.

18 Radaelli F, Meucci G, Sgroi G, et al: Technical performance of colonoscopy: the key role of sedation/analgesia and other quality indicators. Am J Gastroenterol 2008;103:1122-1130. 